\section{Reimagining Professional Meetings: Another Lesson From COVID-19}

B ecause this is November, I should probably be writing about things I am thankful for. So, after family, friends, and good health, I would have to put reuniting with colleagues right at the top of the list. As I write, I am just back from my first professional meeting -in person! For me, being there in person is the way to go, but I also got a glimpse of what a hybrid meeting might look like. As well as how we will endure the lingering risk of COVID.

Let's start with COVID. The meeting organizers required masks inside the lecture hall unless you were speaking, and thoughtfully put 6 feet of distance between participants in the audience. However, on dais for the panel discussion, faculty sat side by side with no masks, and during the coffee break, everyone took off masks to drink coffee and eat pastries, chatting side by side. The inconsistency in practice was very evident. I personally think the time has come to forget the masks if you are fully vaccinated; conversely, I recommend that those who are immunosuppressed or unvaccinated or worry about acquiring a breakthrough infection attend virtually. It is just too hard to mix it up in social settings.

As for the hybrid meeting, there were about 60 participants in person and 100 online, including several faculty members. I was very impressed with the technology they used for the faculty. As virtual speakers, they were live, not recorded, and I suspect they were using special camera equipment. These people were not talking into their computer cameras. They looked straight at you and were interactive with other panel members or as co-chairs. It seemed quite seamless. During the break, the faculty stayed with you on robot computers and visited with you around the refreshment tables. Pretty cool!

Because I was there in person, I don't know what the experience was like for virtual attendees. I know I am tired of virtual meetings, but when they are live rather than recorded, it's a bit better. Spontaneity keeps it interesting. So, for those times when cost or schedules do not permit travel, having a virtual option is better than nothing. And good camerawork and other technology makes a big difference.

Of course, going in person means travel of some sort. This was my first airplane trip for professional reasons, and now I remember why my stress level was much improved when I was homebound. The airports were crowded. My flight was delayed. I nearly missed my connection. The person behind me on the trip home looked and sounded as if he was very sick with COVID. Yikes! I was very glad to get home.

All the negatives aside, I am ready to head out again. I have missed my tribe, and it is very good to be back with them. People do need people. JNCCN@nccn.org or log into www.editorialmanager.com/JNCCN.

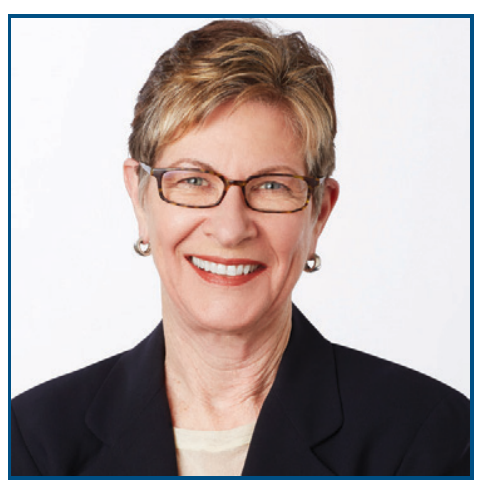

MARGARET TEMPERO, MD

Margaret Tempero, MD, is a Professor of Medicine and Director of the UCSF Pancreas Center and editor-in-chief of JNCCN. Her research career has focused on pancreatic ductal adenocarcinoma, especially in the area of investigational therapeutics. Dr. Tempero has served on the ASCO Board of Directors and as ASCO President. She currently serves on the ASCO Conquer Cancer Foundation Board. She codirected the AACR/ASCO Methods in Clinical Cancer Research and taught this course and similar courses in Europe and Australia. She was founding Chair of the $\mathrm{NCl}$ Clinical Oncology Study Section and served as a member and Chair of the $\mathrm{NCl}$ Board of Scientific Counselors Subcommittee A. She is a member of the Scientific Steering Committee and Chair of the Clinical and Translational Study Section for the Cancer Prevention \& Research Institute of Texas. She is or has been on the Scientific Advisory Boards of the Lustgarten Foundation, the Pancreatic Cancer Action Network, the V Foundation, The Alberta Canada Cancer Board, and the EORTC. She served as a member of the Oncology Drug Advisory Committee for the FDA. She has served as Deputy Director and Interim Director for the UNMC Eppley Cancer Center. She is Chief Emeritus of the Division of Medical Oncology at UCSF. She served as the founding Deputy Director and was later Director of Research Programs at the UCSF Helen Diller Family Comprehensive Cancer Center.

doi: 10.6004/jnccn.2021.0055

The ideas and viewpoints expressed in this editorial are those of the author and do not necessarily represent any policy, position, or program of NCCN 